\title{
A Systematic Review of Survival of Children with Solid Tumors in Low- and Middle-Income Countries
}

\author{
Eliana Marostica ${ }^{1}$, Sarah Barbrow ${ }^{2}$, Nickhill Bhakta ${ }^{3}$, Lisa Force ${ }^{3}$, Paola Friedrich ${ }^{4}$, Sara \\ Lederman $^{5}$, Becky Lee ${ }^{6}$, Meaghan Muir ${ }^{7}$, Emily Shohfir ${ }^{7}$, Alexandra Power-Hays ${ }^{8}$, Allison \\ Pribnow $^{9}$, Adriana Ramirez ${ }^{10}$, Thomas Alexander ${ }^{11}$, Leslie Robison ${ }^{3}$, and Lindsay Frazier ${ }^{12}$ \\ ${ }^{1}$ Wellesley College Department of Computer Science \\ ${ }^{2}$ Wellesley College \\ ${ }^{3}$ St Jude Children's Research Hospital \\ ${ }^{4}$ Saint Jude Children's Research Hospital \\ ${ }^{5}$ University of Minnesota Medical School Twin Cities \\ ${ }^{6}$ Loma Linda University Medical Center Department of Radiation Medicine \\ ${ }^{7}$ Boston Children's Hospital \\ ${ }^{8}$ Boston Children's Hospital Department of Pediatrics \\ ${ }^{9}$ Stanford University School of Medicine \\ ${ }^{10}$ University of Virginia Department of Surgery \\ ${ }^{11}$ University of North Carolina System \\ ${ }^{12}$ Dana-Farber Cancer Institute Department of Pediatric Oncology
}

October 13, 2020

\begin{abstract}
Population-level estimates of the survival of children from low- and middle-income countries diagnosed with solid tumors do not currently exist, in contrast to outcomes of hematologic and central nervous system cancers, which have been collated from population-based cancer registries and published by the CONCORD Programme. To fill this knowledge gap, we conducted a systematic review of PubMed Legacy, Embase, Web of Science, Cochrane Central Registry of Controlled Trials, and three regional databases for publications that reported survival of children diagnosed age 0-14 years with any malignancy from January 2011 to December 2016. The search identified 4695 original records; 51 articles met inclusion criteria. The range of survival reported was broad; for instance, 5-year overall survival for retinoblastoma ranged from $48 \%$ in Central America to $98 \%$ in China. However, the paucity of published statistics prevented approaches for meta-analyses and emphasizes the need for more standardized data collection and reporting.
\end{abstract}

\section{Hosted file}

Marostica_MainText_PBC.pdf available at https://authorea.com/users/366730/articles/486402a-systematic-review-of-survival-of-children-with-solid-tumors-in-low-and-middle-incomecountries

\section{Hosted file}

Table1.pdf available at https://authorea.com/users/366730/articles/486402-a-systematicreview-of-survival-of-children-with-solid-tumors-in-low-and-middle-income-countries 
PRISMA 2009 Flow Diagram

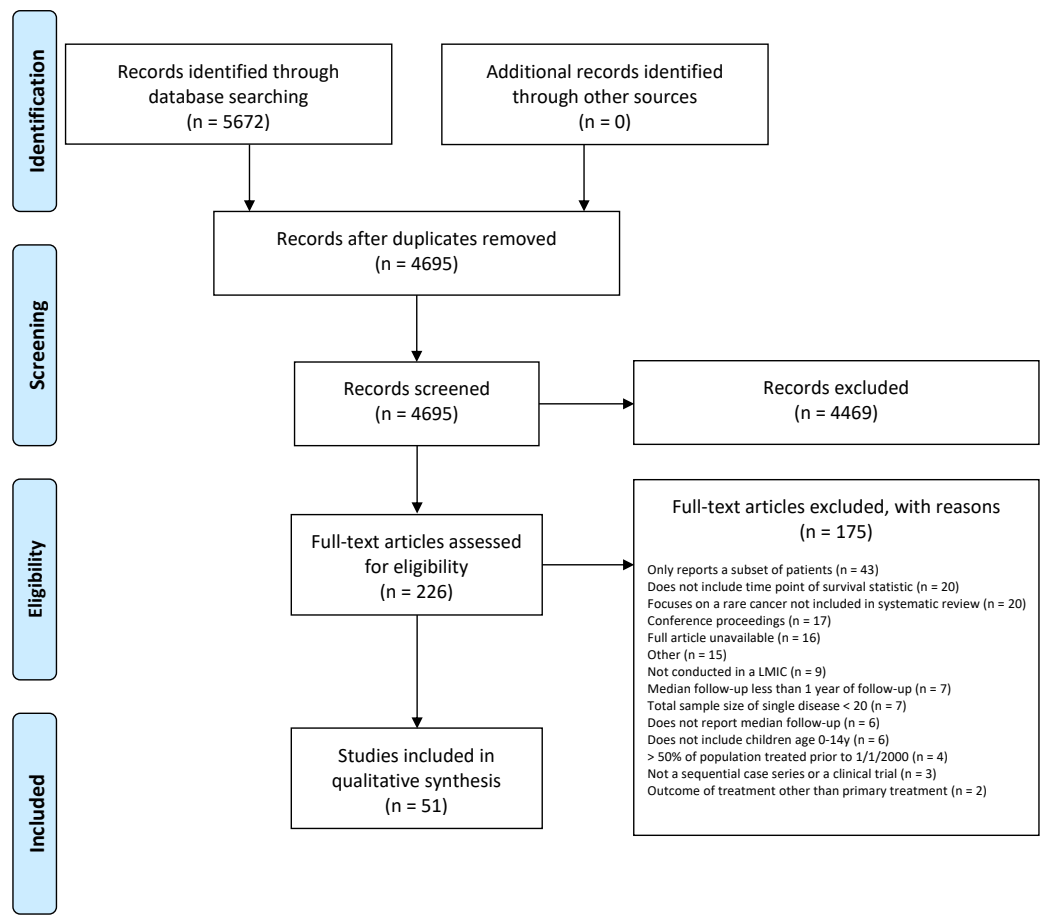

From: Moher D, Liberati A, Tetzlaff J, Altman DG, The PRISMA Group (2009). Preferred Reporting /tems for Systematic Reviews and MetaAnalyses: The PRISMA Statement. PLoS Med 6(7): e1000097. doi:10.1371/journal.pmed1000097

For more information, visit www.prisma-statement.org. 
Income $\quad$ Low $\square$ Lower-Middle $\square$ Upper-Middle
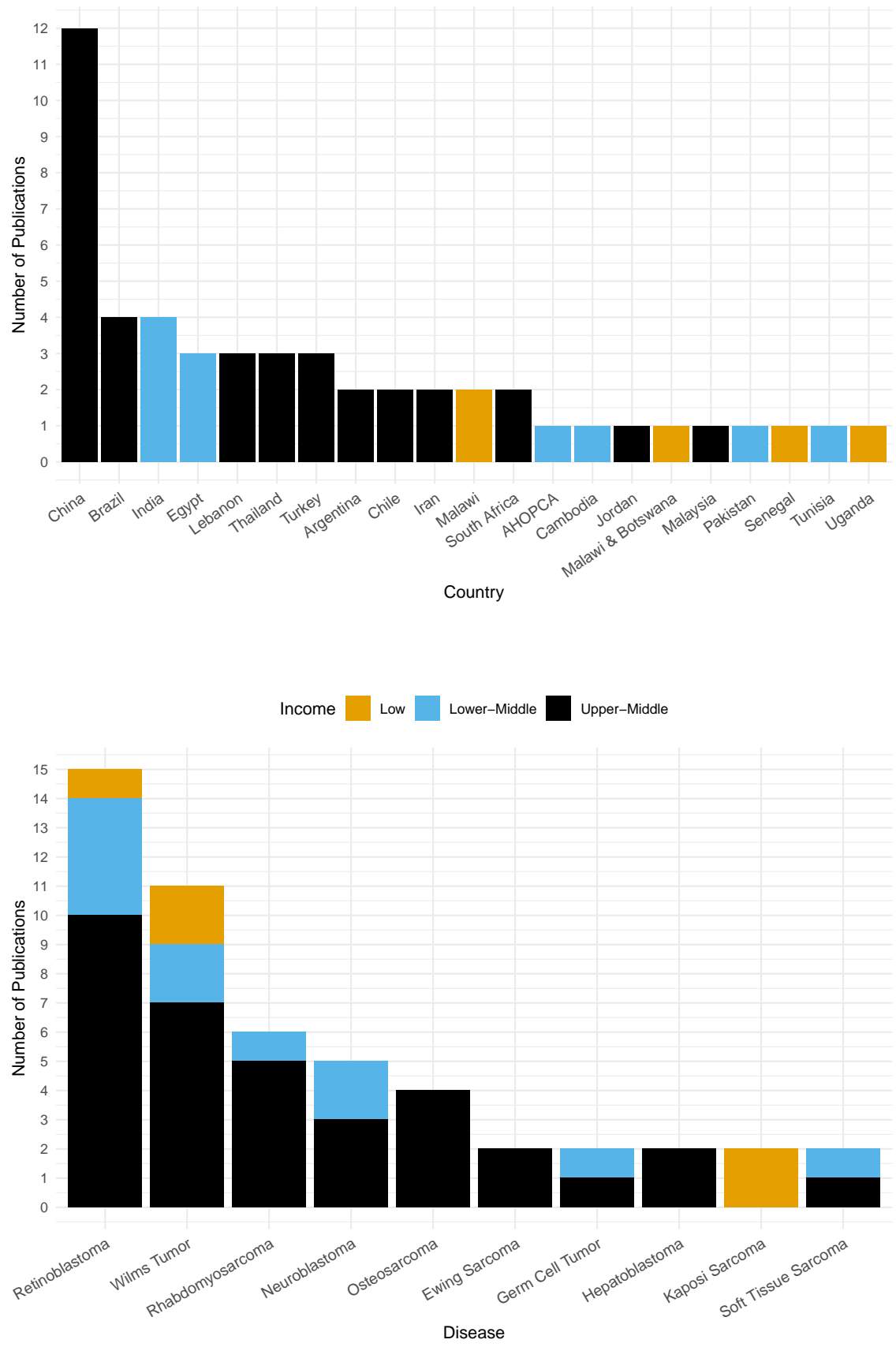

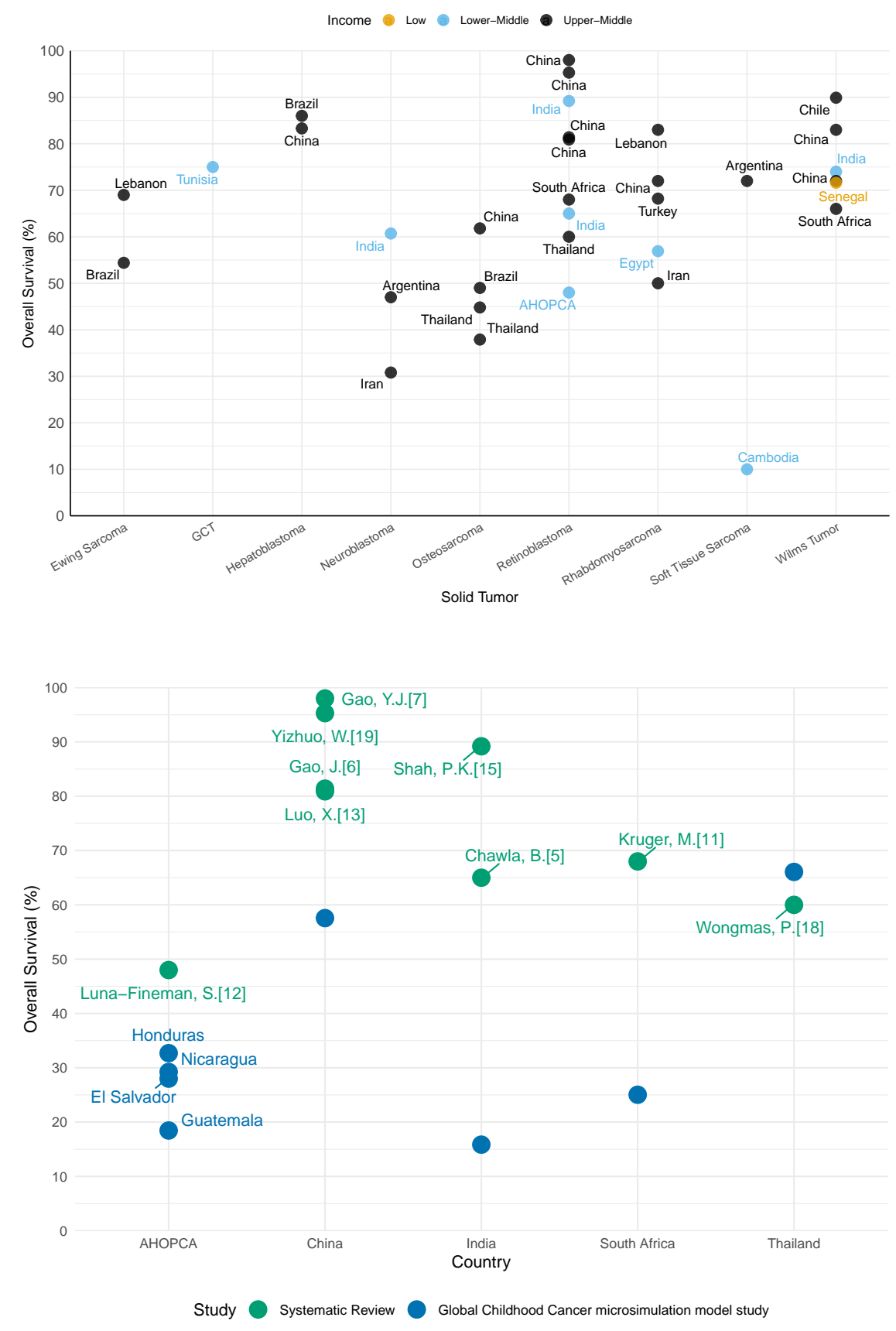


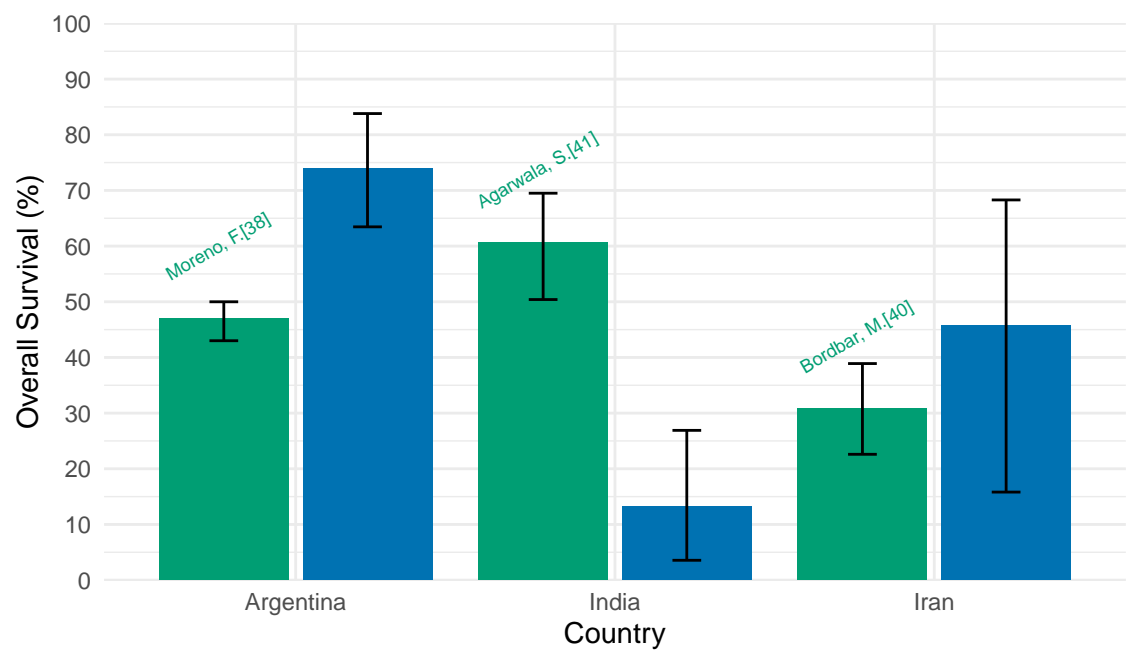

Study Systematic Review

Global Childhood Cancer microsimulation model study 